\title{
Öz-Yönetimli Öğrenme Becerileri Ölçeği: Geçerlik ve Güvenirlik Çalışması*
}

\author{
Self Directed Learning Skills Scale: Validity and Reliability \\ Study
}

\author{
İlkay AŞKIN TEKKOL **
}

Melek DEMIREL ***

\section{$\ddot{\mathbf{O} z}$}

$\mathrm{Bu}$ araştırmanın amacı üniversite öğrencilerinin öz-yönetimli öğrenme becerilerini belirlemeye yönelik bir ölçme aracı geliştirmektir. Bu amaçla öncelikle, ilgili alanyazına dayalı olarak kavramsal çerçeve oluşturulmuş, bu alanda yurt içi ve yurt dışında yapılmış olan ölçek geliştirme çalışmaları incelenmiştir. Bu incelemenin ardından, ölçeğe ilişkin ölçütler ortaya konmuş ve öz-yönetimli öğrenme becerilerine sahip bireylerin özelliklerini ifade eden maddelerden oluşan 72 maddelik madde havuzu oluşturulmuştur. Uzman görüşlerinin ardından yapılan düzenlemeler sonucunda, ölçeğin 53 maddelik deneme formu oluşturulmuştur. $\mathrm{Bu}$ form, Hacettepe ve Başkent Üniversitelerinde öğrenim görmekte olan 753 üniversite öğrencisine uygulanarak, veriler açımlayıcı faktör analizine tabi tutulmuş ve yapılan analiz sonucunda ölçeğin 21 madde ve dört boyuttan (güdülenme, öz-izleme, öz-kontrol ve özgüven) oluştuğu ortaya konmuştur. Ayrıca, açımlayıcı faktör analizinin uygulandığı öğrencilerin dışında yer alan ve Hacettepe ve Başkent Üniversitelerinin ortak olan bölümlerinin birinci ve dördüncü sınıflarında öğrenim görmekte olan 2600 öğrenciye ölçek uygulaması yapılarak ölçeğin yapı geçerliğinin belirlenmesi amaçlanmıştır. Toplanan veriler doğrulayıcı faktör analizine tabi tutulmuştur. Analiz sonucunda ölçeğe ilişkin uyum indekslerinin iyi uyum gösteren ve kabul edilebilir değerler arasında olduğu görülmüş ve ölçeğin 4 faktörlü ve 21 maddeden oluşan yapısı bir model olarak doğrulanmıştır. Ölçeğin, Cronbach Alpha iç tutarlık katsayısı kullanılarak hesaplanan güvenirliği ise .895 bulunmuştur. Sonuç olarak geliştirilen “Öz-Yönetimli Öğrenme Becerileri Ölçeği”nin, geçerli bir ölçme aracı olduğu ve öz-yönetimli öğrenme becerilerini ölçmede güvenilir puanlar vereceği söylenebilir.

Anahtar Kelimeler: Öz-yönetimli öğrenme, öz-yönetimli öğrenme becerileri, ölçek geliştirme, üniversite öğrencileri

\begin{abstract}
The aim of this study was to develop a psychometric scale that aims to measure self-directed learning skills of undergraduate students. The literature was first reviewed, and a conceptual framework was established to identify the basic characteristics of the scale. In addition, similar scale development studies in and outside Turkish literature were examined. After then, criteria were execute which related scale and a 72-item pool was formed, and it was revised in line with expert views, and a version with remaining 53item was implemented on 753 students attending Hacettepe and Başkent Universities. The data were implemented exploratory factor analysis. It was found that the scale consisted of four sub-scales (motivation, self-control, self-monitoring and self-confidence), and twenty one items associated with the sub-scales. Also, in order to determine the construct validity of the scale, a confirmatory factor analysis was carried out with 2600 students attending Hacettepe and Başkent Universities. This second group of students were the first and last year of students in the common programs in both universities. The fit indices of the scale showed good or acceptable values. According to this, the 21-item and four-factor structure of the 'Self-Directed Learning Skills Scale' was confirmed as a model. The Cronbach Alpha internal consistency coefficient was ,895. As a result, it was concluded that the "Self-

\footnotetext{
* Bu çalışma birinci yazarın doktora tezinden üretilmiştir. (Üniversite Öğrencilerinin Öz-Yönetimli Öğrenme Becerilerinin İncelenmesi, Danışman: Doç. Dr. Melek DEMİREL, 2015)

** Dr. Öğr. Üyesi, Kastamonu Üniversitesi, Eğitim Fakültesi, Kastamonu-Türkiye, e-posta:ilkayaskin@hotmail.com, ORCID ID: orcid.org/0000-0003-0964-1528 orcid.org/0000-0002-2449-5824
}

*** Prof. Dr., Hacettepe Üniversitesi, Eğitim Fakültesi, Ankara-Türkiye, e-posta:melekdemirel@gmail.com, ORCID ID:
\end{abstract}

Eğitimde ve Psikolojide Ölçme ve Değerlendirme Dergisi, Cilt 9, Sayı 2, Yaz 2018, 85-100.

Journal of Measurement and Evaluation in Education and Psychology, Vol. 9, Issue 2, Summer 2018, 85-100. 
directed Learning Skills Scale" was a valid measurement tool and produced reliable scores for measuring selfdirected learning skills.

Keywords: self-directed learning, self-directed learning skills, scale development, undergraduate students

\section{GÍRIŞ}

Bilginin, bilgiyi sağlayan otoriteler tarafından değişmez parçalar halinde bireylere aktarılması anlayışı, günümüzde pek çok farklı kaynaktan bilgiye ulaşılabiliyor olması nedeniyle değişikliğe uğramıştır. $\mathrm{Bu}$ sayede, bireylerin bilgileri ezber yolu ile doğrudan almaları düşüncesi yerine, bireylerin bilgileri kavrama ve sorgulama yoluyla ele almaları görüşü giderek artan bir önem kazanmıştır. Bu durumda, herhangi bir disipline ilişkin bilgiyi ezberlemek yerine, bilginin doğasını kazanmak, bilgiye ulaşma yolunu öğrenmek; diğer bir deyişle öğrenmeyi öğrenmek önemli bir hale gelmiştir.

Öğrenmeyi öğrenme, önceleri öğrencinin daha çok öğrenmesi anlamında kullanılırken; artan bilgi miktarı ve öğrencilerin öğrenmeye harcadıkları zamanın artması nedeniyle değişikliğe uğramıştır (Csapo, 2007). Wingate (2007) öğrenmeyi öğrenmenin iki temel öğesi olduğunu ifade etmektedir. Bu öğeler: (1) "öğrenme”yi anlama ve bağımsız öğrenen olma ve (2) "bilgi”yi anlama ve bilgiyi yapılandırma konusunda yeterli olmadır. Wingate'e (2007) göre bu öğeler öğrenmeyi öğrenen bireylerin yetişmesi konusunda büyük bir öneme sahiptir ve her iki öğe de belirli özellikleri içermektedir. Bu özellikler şu şekilde açıklanabilir (Wingate, 2007):

1. Öğrenmeyi anlama ve bağımsız öğrenen olma
a. ̈ğrenme anlayışları konusunda farkındalık kazanma
b. Öğrenen olarak yeteneklerini değerlendirme
c. Kisa ve uzun vadeli hedefler belirleme
d. Hedeflere ulaşma konusunda planlama yapma
e. Hedeflere ulaşırken süreci gözden geçirme
f. Başarıyı ve süreci değerlendirme

2. Bilgiyi anlama ve bilgiyi yapılandırma konusunda yeterli olma
a. Disiplin içindeki bilgiyi fark etme
b. Odaklı bir şekilde bilgiye (ders notu, kitaplar) başvurma
c. Var olan bilgiyi değerlendirme
d. Farklı kaynakları tutarlı bir şekilde bir araya getirme/sentezleme
e. Kendini ifade etme

En yalın ifade ile öğrenmeyi öğrenen bireyler, kendi öğrenmelerini yönetebilen bireylerdir. Alanyazında da öğrenmeyi öğrenme becerisi; öz-yönetimin temel ilkelerinden biri olarak kabul edilmektedir (Salas, 2010). Öz-yönetim, bireyin öğrenmesinin kendi kontrolünde olması, diğer bir deyişle öğrenenin kendi öğrenmesini yönetebilmesidir.

Öz-yönetimli öğrenme ise en geniş anlamda, bireylerin öğrenme ihtiyaçlarını belirleme, öğrenme hedeflerini ortaya koyma, ögrenme konusunda ihtiyaç duydukları kaynakları tanımlama, uygun öğrenme stratejilerini seçme/kullanma ve öğrenme çıktılarını değerlendirme konusunda başkalarının yardımı ile ya da yardımı olmaksızın inisiyatif almalarını ifade etmektedir (Knowles, 1975). Özyönetimli öğrenme, öğrenme sorumluluğunun bir kaynaktan (öğretmen, vb.), bireyin kendisine doğru yön değiştirmesi sürecini içermektedir. Burada, öğrenenin öğrenme sürecindeki kontrolü ve etkin 
katılımı büyük bir öneme sahiptir (Boyer ve Usinger, 2015; Grover, 2015). Bu kontrol sayesinde bireyler kendi öğrenmelerini düzenleyebilmekte ve hedeflerini belirleyebilmektedirler. Bireyler belirledikleri hedeflere ulaşabilmek için öğrenme sorumluluğunu üstlenerek bireysel tercihlerde bulunabilirler (Kaufman, 2003). Öz-yönetimli öğrenmede aynı zamanda, bireyin öğrenme konusundaki güdülenme düzeyi de büyük bir önem taşımaktadır (Song ve Hill, 2007).

Öz-yönetimli öğrenme, farklı amaçları içermektedir. Bu konudaki yazarların felsefi yönelimlerine göre, öz-yönetimli öğrenmenin üç temel amacından söz edilebilir. Öz-yönetimli öğrenmenin ilk amac1; öğrenenlerin öz-yönetimli öğrenme konusunda kendilerini geliştirmelerinin sağlanmasıdır. $\mathrm{Bu}$ amacı gerçekleştirebilmek için, bireylerin özelliklerine uygun olarak becerilerinin özelleştirilmesi gerekmektedir. İkinci amaç, öz-yönetimli öğrenme özelinde dönüştürücü öğrenmeyi (transformational learning) teşvik etmektir. Dönüştürücü öğrenme, Mezirow’un (1991) ortaya koyduğu, öğrenenlerin öğrenmede eleştirel yansıtmayı merkeze aldıkları bir süreçtir. Burada yer alan eleştirel yansıtma, bireyin ihtiyaçlarının, isteklerinin ve ilgilerinin tarihi, kültürel ve biyolojik nedenlerini anlama olarak ifade edilmektedir. Mezirow (1991) böyle bir öz-bilginin, öz-yönetimli öğrenmede bağımsızlığın sağlanabilmesi için bir ön koşul olduğunu belirtmektedir. Öz-yönetimli öğrenmenin üçüncü amacı, özgürlükçü öğrenmeyi ve sosyal etkinlikleri teşvik etmektir. Alanyazında Brookfield ve Collins gibi araştırmacılar, öz-yönetimli öğrenmenin, bireysel öğrenmeden çok sosyal ve politik etkinliklerinden söz etmekte ve öz-yönetimli öğrenmenin eleştirel ve politik analizleriyle ilgilenmektedirler (Merriam, Caffarella ve Baumgartner, 2007).

Öz-yönetimli öğrenme, bireylerin özgüvenlerinin, özerkliklerinin, güdülenmelerinin artması ve yaşam boyu öğrenme becerilerinin gelişmesini sağlamaktadır (O’Shea, 2003). Bunun yanı sıra, özyönetimli öğrenme öğrenenlerin etkin katılımcılar olmalarını sağlamakta ve derinlemesine öğrenen öğrenciler olmaları konusunda onları cesaretlendirmektedir (Spencer ve Jordan, 1999). Ancak bireylerin, öz-yönetimli öğrenenler olabilmeleri için sahip olmaları gereken bir takım yeterlikler bulunmaktadır. Bu yeterlikler Knowles (1977) tarafından şu şekilde açıklanmıştır:

- Öğrenenlerle yakın, saygılı ve öğrenmeyi kolaylaştırıcı bir ilişki içerisinde bulunma becerisi

- Fiziksel ve psikolojik olarak rahat, etkileşime açık, işbirliğine dayalı, açık ve karş1lıklı güvene dayalı bir ortam oluşturma becerisi

- Bireylerin öğrenme konusundaki ihtiyaçlarını belirleme sorumluğunu almaları

- Bireylerin hedeflerini belirleme becerisi

- Bireylerin öğrenme etkinliklerini planlama, yürütme ve değerlendirme becerisi

- Öğrenenlere öz-yönetimli olabilmeleri konusunda yardım etme becerisi

- Küçük grup süreçlerini etkili bir şekilde kullanma becerisi

- Öğrenme süreçlerini ve çıtıllarını değerlendirme becerisi (Knowles 1977; akt. Kasworm, 1983).

Knowles'un üzerinde durduğu bu yeterliklere sahip bireylerin öz-yönetimli öğrenen bireyler oldukları ifade edilebilir. Savin-Baden ve Major'a (2004) göre öz-yönetimli öğrenenler; açık hedefler koyan, bir plan doğrultusunda ilerleyen, görevlerini takip eden ve normal sınırlarını yüksek standartlara ulaşmak için zorlayan bağımsız, öz-güdülenmeye sahip bireylerdir. Ayrıca, öz-yönetimli öğrenenlerin, öğrenmeye açık, meraklı, düzenli, güdülenmiş ve hevesli bireyler olduğu; öğrenmeye değer verdikleri ve öz-kontrollü oldukları; bunun yanı sıra, belirsizlik ve değişiklik konusunda rahat oldukları ifade edilmektedir (Jennett, 1992).

\section{Araştırmanın Amacı}

Öz-yönetimli öğrenenler; kendilerine net hedefler koyan, planlı hareket eden, insiyatif alan, öğrenmeye açık, güdülenmiş, kendilerine güvenen ve öz-kontrollü bireylerdir. Bu özellikler bilginin 
hızla değiştiği ve katlanarak arttığı günümüzde, çağa ayak uydurabilecek bireylerin sahip olmaları gereken nitelikler arasında yer almaktadır. Kendi öğrenmesini yönetebilen bireyler; bilgiye ulaşma yollarını kazanmış, üst düzey düşünebilen ve kendi öğrenmesini düzenleyebilen, kısaca öğrenmeyi öğrenmiş bireylerdir. Üniversite öğrencilerinin bu özelliklere sahip olmaları, onların üniversite yaşamından sonra da gerek kişisel gerek mesleki olarak kendini geliştirmelerini, öğrenme isteği taşımalarını, öğrenmeye açık olmalarını ve öğrenmelerini sürdürme eğiliminde olmalarını; kısaca yaşam boyu öğrenenler olmalarını sağlayacaktır. Bu bağlamda üniversite öğrencilerinin öz-yönetimli ögrenme becerilerinin belirlenmesi önemli görülmektedir. Bu becerilerin tespit edilebilmesi için ise geçerli ve güvenilir bir ölçme aracının kullanılması gerekmektedir. Bu kapsamda bu araştırmanın amac1, üniversite öğrencilerinin öz-yönetimli öğrenme becerilerinin belirlenmesini sağlayacak geçerli ve güvenilir bir ölçek geliştirmektir.

Alanyazında, öz-yönetimli öğrenme konusundaki ölçek geliştirme çalışmaları incelendiğinde yurt dışında geliştirilen çeşitli ölçekler bulunmakla birlikte; yurt içinde öz-yönetimli öğrenme becerilerini ölçmek amaciyla kullanılan ölçeklerin genellikle yurt dışından uyarlanan ölçekler olduğu görülmektedir (Demir ve Yurdagül, 2013; Kocaman, Dicle, Üstün ve Çimen, 2004; Salas, 2010; Sasa, 2011; Şahin, 2013; Şahin ve Erden, 2008). Bunun yanı sıra, yurt içinde geliştirilen az sayıda ölçeğin, öğrencilerin öz-yönetimli öğrenme becerilerine ilişkin belirli özellikleri ölçmek üzere geliştirilen alana özgü ölçekler olduğu ortaya konmuştur (Acar, 2014; Alkan ve Erdem, 2013; Aydede ve Kesercioğlu, 2009). Bu ölçeklerin, ilköğretim öğrencilerinin fen ve teknolojiye ilişkin özyönetimli öğrenme becerileri, öğretmen adaylarının öz-yönetimli öğrenme becerileri, hemşirelik bölümü öğrencilerinin öz-yönetimli öğrenme becerileri gibi öz-yönetimli öğrenmeye ilişkin daha özelleşmiş ölçekler olduğu, üniversite öğrencilerinin öz-yönetimli öğrenme becerilerini genel olarak ölçmeye yönelik ölçeklerin olmadığı görülmektedir. Uyarlanan ölçeklerden Guglielmino'nun (1977) ölçeğinin geçerliğine ilişkin sorunların ortaya konması (Field, 1989) ve Fisher, King ve Tague'nin (2001) ölçeğinin de hemşirelik ve eğitim fakültesi gibi alanlara uygun olarak uyarlanmış olması sebebiyle bu alanda yeni ve kapsamlı bir ölçek geliştirilmesi gerekli görülmüştür. Bu kapsamda araştırmada, tüm üniversite öğrencilerinin öz-yönetimli öğrenme becerilerini ortaya koymak amacıyla “Öz-yönetimli Öğrenme Becerileri Ölçeği”nin geliştirilmesi amaçlanmıştır.

\section{YÖNTEM}

$\mathrm{Bu}$ araştırma bir ölçek geliştirme çalışmasıdır. Araştırmada üniversite öğrencilerinin öz-yönetimli öğrenme becerilerinin tespit edilebilmesi amaciyla "Öz-Yönetimli Öğrenme Becerileri Ölçeği”" geliştirilmiştir. Ölçek geliştirmeye ilişkin adımlar sırasıyla açıklanmıştır.

\section{Çalışma Grupları}

Araştırmada, açımlayıcı faktör analizi ve doğrulayıcı faktör analizi ayrı gruplar üzerinde yapılmıştır. Araştırmada devlet üniversitesi olarak gelişmiş ve araştırmacılar açısından kolay ulaşılabilir bir üniversite olduğu için Hacettepe Üniversitesi ve bu üniversite ile ortak fakülte ve bölümlere sahip olması nedeniyle özel üniversite olarak Başkent Üniversitesi seçilmiştir. Çalışma gruplarına her iki üniversitede ortak olan bölümlerde öğrenim gören öğrenciler dahil edilmiştir. Çalışma gruplarına ilişkin bilgiler aşağıda yer almaktadır:

\section{Çalışma grubu 1}

Araştırmanın çalışma grubunu Hacettepe ve Başkent Üniversitelerinde öğrenim gören öğrenciler oluşturmuştur. Öğrencilere ilişkin bilgiler Tablo 1'de sunulmuştur. 
Tablo 1. Açımlayıcı Faktör Analizinin Uygulandığı Çalışma Grubu

\begin{tabular}{lc}
\hline Fakülte & Öğrenci Sayıs1 \\
\hline Eğitim Fakültesi & 173 \\
Fen-Edebiyat Fakültesi & 141 \\
Güzel Sanatlar Fakültesi & 40 \\
Devlet Konservatuvarı & 6 \\
Hukuk Fakültesi & 115 \\
İktisadi ve İdari Bilimler Fakültesi & 91 \\
Mühendislik Fakültesi & 90 \\
Sağlık Bilimleri & 110 \\
\hline Toplam & 766 \\
\hline
\end{tabular}

Ölçeğin deneme formu Tablo 1'de görüldüğü gibi 766 öğrenciye uygulanmıştır. Bu formlardan eksik ya da hatalı doldurulan Tablo 1 incelendiğinde, 13 form çıkarılmıştır. Sonuç olarak açımlayıcı faktör analizi 753 öğrencinin verisi ile gerçekleştirilmiştir.

\section{Çalışma grubu 2}

Doğrulayıcı faktör analizi açımlayıcı faktör analizinin yapıldığı gruptan farklı bir grup üzerinde uygulanmıştır. Ölçeğinin yapısının doğrulanması amacıyla, Ankara ilinde bulunan Hacettepe ve Başkent Üniversitelerinin Mühendislik, Tıp, Diş Hekimliği, Güzel Sanatlar, Hemşirelik, Sağlık Bilimleri, İktisadi ve İdari Bilimler, Eğitim ile Fen ve Edebiyat fakülteleri ile Devlet Konservatuvarının birinci ve dördüncü sınıflarında öğrenim görmekte olan 2600 üniversite öğrencinin verileri doğrulayıcı faktör analizine tabi tutulmuştur (Bilgisayar, Elektrik Elektronik, Endüstri Mühendislikleri, Tıp Fakültesi, Diş Hekimliği, Hemşirelik, Sosyal Hizmet, Beslenme ve Diyetetik, Fizyoterapi ve Rehabilitasyon, İşletme, İktisat, Psikoloji, Türk Dili ve Edebiyatı, Okul Öncesi, Sınıf, İlköğretim Matematik, İngilizce Öğretmenlikleri ve Psikolojik Danışma ve Rehberlik, İç Mimarlık ve Çevre Tasarımı, Grafik, Müzik/Sahne Sanatları). Çalışma grubuna ilişkin bilgiler Tablo 2'de yer almaktadır.

Tablo 2. Doğrulayıcı Faktör Analizinin Uygulandığı Çalışma Grubu

\begin{tabular}{lll}
\hline Konu Alanları & Bölümler & Öğrenci Sayısı \\
\hline Fen Bilimleri & Bilgisayar Müh. & 444 \\
& Elektrik Elektronik Müh. & \\
& Endüstri Müh. & \\
& İlköğretim Matematik Öğrt. & \\
\hline Güzel Sanatlar & Grafik & 142 \\
& İç Mimarlık ve Çevre Tasarımı & \\
& Müzik/Sahne Sanatları & \\
\hline Sağlık Bilimleri & Beslenme ve Diyetetik & 1105 \\
& Diş Hekimliği & \\
& Fizyoterapi ve Rehabilitasyon & \\
& Hemşirelik & \\
& Sosyal Hizmet & \\
& Tip \\
\hline Sosyal Bilimler & Türk Dili ve Edebiyatı & \\
& Psikoloji & \\
& Okul Öncesi Öğrt. & \\
& Sinıf Öğrt. \\
& İngilizce Öğrt. & \\
& Rehberlik ve Psikolojik Dan. \\
& İktisat, İşletme \\
&
\end{tabular}


Tablo 2'ye göre doğrulayıcı faktör analizinin uygulandığı çalışma grubunu, Bilgisayar Elektrik Elektronik, Endüstri Mühendislikleri ve İlköğretim Matematik Öğretmenliği bölümlerinde öğrenim gören olan 444; Grafik, İç Mimarlık ve Çevre Tasarımı ve Müzik/Sahne Sanatları bölümlerinde öğrenim gören 142; Beslenme ve Diyetetik, Diş Hekimliği, Fizyoterapi ve Rehabilitasyon, Hemşirelik, Sosyal Hizmet ve Tıp alanlarında öğrenim gören 1105; Türk Dili ve Edebiyatı, Psikoloji, Okul Öncesi, Sınıf, İngilizce Öğretmenlikleri, Rehberlik ve Psikolojik Danışma, İktisat ve İşletme bölümlerinde öğrenim görmekte olan 909 üniversite öğrencisi oluşturmuştur. Doğrulayıcı faktör analizi toplam 2600 öğrencinin verisi üzerinde uygulanmıştır.

\section{İşlem}

Ölçeğin geçerliğinin ortaya konması amacıyla, kapsam ve yapı geçerliği çalışmaları yapılmıştır. Ölçeğin kapsam geçerliği belirlenirken öncelikle ilgili alanyazını incelenmiş ve bu doğrultuda kavramsal çerçeve oluşturularak, ölçeğe ilişkin temel özellikler ortaya konmuştur. Bu özellikler belirlenirken bu alanda yurt içi ve yurt dışında yapılmış olan ölçek geliştirme çalışmaları incelenmiş ve ölçek maddelerini oluşturmak amacıyla bir grup üniversite öğrencisi ile görüşmeler yapılmıştır. Bunun sonucunda ölçeğe ilișkin temel ölçütler tespit edilmiștir. Bu ölçütler öğrenme ihtiyacını belirleme, öğrenme amacını belirleme, öğrenme sonuçlarını değerlendirme, farklı öğrenme stratejilerini kullanma, öğrenme sürecini izleme, planlama yapma, öğrenmeyi sevme, öğrenmekten vazgeçmeme/öğrenmede sebat, kendine güven/benlik algısı, öğrenme sorumluluğunu alma, girişkenlik ve bağımsızlık olarak belirlenmiştir. Ölçütlerin ortaya konmasının ardından, 72 maddelik madde havuzu oluşturulmuş ve yedi eğitim programları ve öğretim, üç ölçme ve değerlendirme bir Türk Dili uzmanına sunularak, uzman görüşleri alınmıştır. Alınan görüşler doğrultusunda ölçekte gerekli düzenlemeler yapılmış ve ölçeğin 53 maddelik deneme formu, 5'li likert tipine göre (her zaman, genellikle, bazen, nadiren, hiçbir zaman) puanlanmıştır.

\section{Verilerin Toplanmast}

Araştırmanın verileri, Hacettepe ve Başkent Üniversitelerinin belirlenen bölümlerinin birinci ve dördüncü sınıflarında öğrenim gören öğrencilerinden, araştırmacı tarafından toplanmıştır. Uygulama öncesinde ilgili üniversitelerin rektörlüklerinden ve dekanlıklarından izin alınarak, uygulamalar, öğrencilerin gönüllü katılımları ile gerçekleştirilmiştir.

\section{Verilerin Analizi}

Toplanan verilerin faktör analizi için uygun olup olmadığının belirlenmesi amacıyla, verilere KaiserMeyer-Olkin (KMO) katsayısı ve Barlett Sphericity testi uygulanmıştır. Ardından, Varimaks rotasyonu ile Temel Bileşenler Analizi kullanılarak açımlayıcı faktör analizi yapılmıştır. Ölçeğin güvenirliğinin hesaplanması amacıyla ise Cronbach Alpha İç Tutarlılık katsayısı hesaplanmıştır. Açımlayıcı faktör analizi SPSS programı ile yapılmıştır.

Doğrulayıcı faktör analizi yapılmadan önce, 2600 öğrencinin verilerindeki uç değerlerin ortaya konması amacıyla Mahalonobis uzaklıkları hesaplanarak, uç değer veren veriler, çalışma grubundan çıkarılmıştır ve 2533 öğrencinin verisi analize dahil edilerek, ölçeğin yapısının doğrulanması amaçlanmıştır. Doğrulayıcı faktör analizi yapılırken, LISREL programından yararlanılmıştır.

\section{BULGULAR}

\section{Açımlayıcı Faktör Analizi}

Toplanan verilerin faktör analizi için uygun olup olmadığının belirlenmesi amacıyla, verilere KaiserMeyer-Olkin (KMO) katsayısı ve Barlett Sphericity testi uygulanmıştır. Analiz sonucunda KMO 
değeri .95 olarak hesaplanmıştır. Bu değer örneklem büyüklüğünün faktör analizi için yeterli olduğu anlamına gelmektedir. Barlett Sphericity testinin sonucunda ise anlamll1ık değeri ,000 bulunmuştur. Buna göre, verilerin faktör analizi için uygun olduğu görülmektedir. Tablo 3'de analiz sonuçları yer almaktadir.

Tablo 3. KMO ve Bartlett Testi Sonuçları

\begin{tabular}{lll}
\hline Kaiser-Meyer-Olkin Örneklem Yeterliği Ölçümü & \multicolumn{2}{c}{, 953} \\
\hline Bartlett's Testi Sonuçları & Yaklaşık Kay-Kare & 14795,919 \\
& Serbestlik derecesi & 1378 \\
& Anlamlılık düzeyi &, 000 \\
\hline
\end{tabular}

Verilerin faktör analizi için uygun olmasının ortaya konması üzerine, verilere Varimaks rotasyonu ile Temel Bileşenler Analizi kullanılarak açımlayıcı faktör analizi yapılmıştır. Faktör analizi ile ölçeğin boyutlarının belirlenmesi amaçlanmıştır. Yapılan açımlayıcı faktör analizine göre, ölçeğin öz değeri 1'den büyük 10 faktörü olduğu görülmüştür. Bu durumda, birden fazla boyutta yük veren maddelerin toplam test korelasyonları, ortak varyansları ve ölçek için kritik olmaları göz önünde bulundurularak maddeler anlamlı bir yapı sergileyene kadar ölçekten sırayla çıkarılmışlardır. Bunun yanı sıra, faktör yükü değeri ,32'nin altında olan maddeler de ölçekten çıkarılmıştır. Tabachnick ve Fidell (2012), ölçekteki maddelerin faktör yükü değerlerinin en az ,32 olması gerektiğini ifade etmektedirler. Yapılan analizler sonucunda, özdeğeri 1'in üzerinde olan 4 faktör ortaya çıkmıştır. Bu faktörlerin ölçeğe ilişkin açıkladıkları toplam varyans \%52,906 olarak belirlenmiştir. Faktörlerin yüklerine ilişkin bilgiler Tablo 4'de yer almaktadır.

Tablo 4. Ölçeğe İlişkin Açımlayıcı Faktör Analizi Sonuçları

\begin{tabular}{lllll}
\hline Maddeler & Faktör 1 & Faktör 2 & Faktör 3 & Faktör 4 \\
\hline m17 &, 758 & & & \\
m30 &, 707 & & & \\
m38 &, 693 & & & \\
m15 &, 641 & & & \\
m9 &, 637 & & & \\
m10 &, 591 & & & \\
m42 &, 555 & & & \\
\hline m46 & &, 738 & & \\
m33 & &, 708 & & \\
m48 & &, 702 & & \\
m31 & &, 651 & & \\
m45 & &, 570 & & \\
\hline m3 & & &, 691 & \\
m5 & & &, 690 & \\
m6 & & &, 681 & \\
m13 & & &, 663 & \\
m12 & & &, 473 & \\
\hline m26 & & & & \\
m36 & & & & \\
m19 & & & & \\
m25 & & & & \\
\hline
\end{tabular}

Ölçeğin boyutları alanyazını ile tutarlı olacak şekilde, güdülenme (7 madde), öz-kontrol (5 madde), öz-izleme (5 madde) ve özgüven (4 madde) olarak belirlenmiştir. Boyutların dağılımına ilişkin grafik ise Şekil 1'de yer almaktadır. 


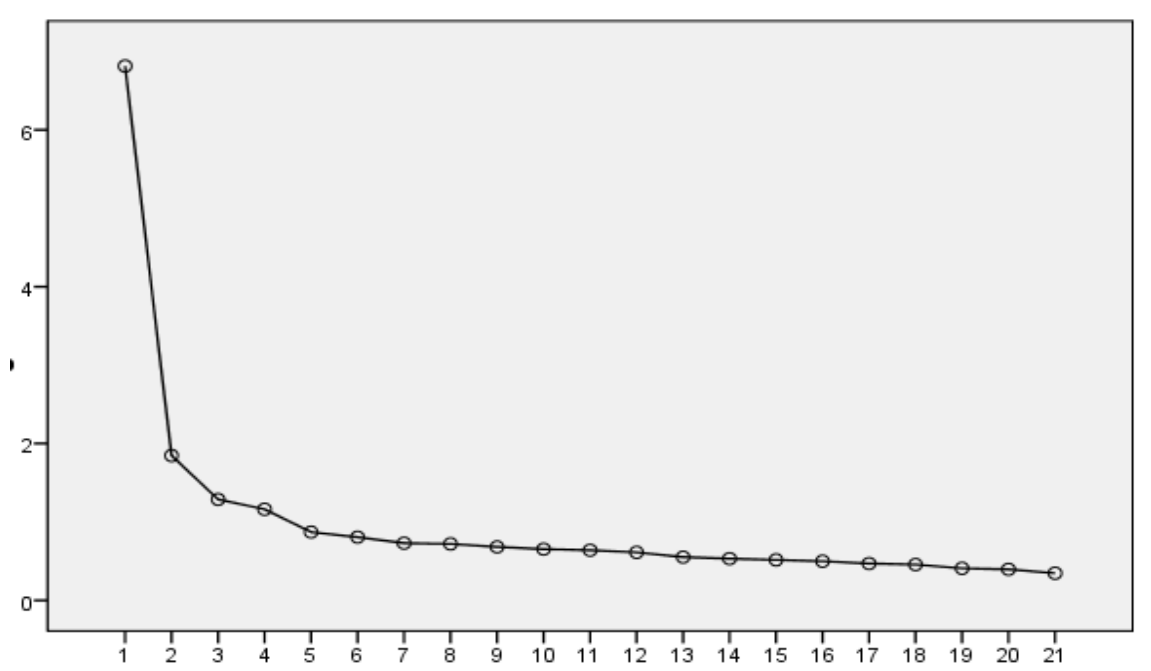

Şekil 1. “Öz-Yönetimli Öğrenme Becerileri” Ölçeğine İlişkin Özdeğer Grafiği

Faktörlere ilişkin özdeğerleri içeren grafik incelendiğinde, ilk faktörden sonra keskin bir düşüş olduğu göze çarpmaktadır. Bu durum ölçeğin genel bir faktöre sahip olabileceği anlamına gelmektedir. Devamındaki üç faktörden sonraki faktörlerin 1'in altında özdeğere sahip olduğu görülmektedir. Bu durumda, ölçeğin 4 boyutlu olduğu kabul edilmiştir.

\section{Doğrulayıcı Faktör Analizi}

Ölçeğinin yapısının doğrulanması amacıyla, 2600 öğrencinin verileri doğrulayıcı faktör analizine tabi tutulmuştur. Doğrulayıcı faktör analizine ilişkin sonuçlar Tablo 5'te yer almaktadır.

Tablo 5. Doğrulayıcı Faktör Analizi Sonuçları

\begin{tabular}{llll}
\hline Boyut & Madde & Standartlaştırılmış değerler & t-değeri \\
\hline Öz-İzleme & OY1 & 0,48 & 24,47 \\
& OY3 & 0,59 & 30,68 \\
& OY7 & 0,64 & 34,01 \\
& OY10 & 0,71 & 39,10 \\
& OY18 & 0,69 & 37,37 \\
\hline Güdülenme & OY2 & 0,49 & 24,60 \\
& OY4 & 0,60 & 30,78 \\
& OY6 & 0,50 & 24,74 \\
& OY8 & 0,60 & 31,33 \\
& OY13 & 0,70 & 37,92 \\
& OY17 & 0,64 & 33,70 \\
& OY21 & 0,78 & 44,11 \\
\hline Öz-Kontrol & OY9 & 0,73 & 40,95 \\
& OY12 & 0,72 & 39,83 \\
& OY14 & 0,74 & 41,60 \\
& OY16 & 0,46 & 22,84 \\
& OY20 & 0,72 & 40,05 \\
\hline Özgüven & OY5 & 0,29 & 12,84 \\
& OY11 & 0,61 & 29,41 \\
& OY15 & 0,58 & 27,72 \\
& OY19 & 0,58 & 27,69 \\
\hline & & &
\end{tabular}

ISSN: 1309 - 6575 Eğitimde ve Psikolojide Ölçme ve Değerlendirme Dergisi 
Tablo 5 incelendiğinde standartlaştırılmış yüklerin 0,29 ile 0,74 arasında değiştiği görülmektedir. Yine tabloya göre tüm $t$ değerlerinin 1,96'nın üzerinde olduğu görülmektedir. Buna göre ölçekteki tüm maddelerin, ilgili olduğu boyutları anlamlı bir şekilde temsil ettiği söylenebilir (Şimşek, 2007). Maddelerin boyutlara göre dağılımına ilişkin veriler Şekil 2'de yer almaktadır.

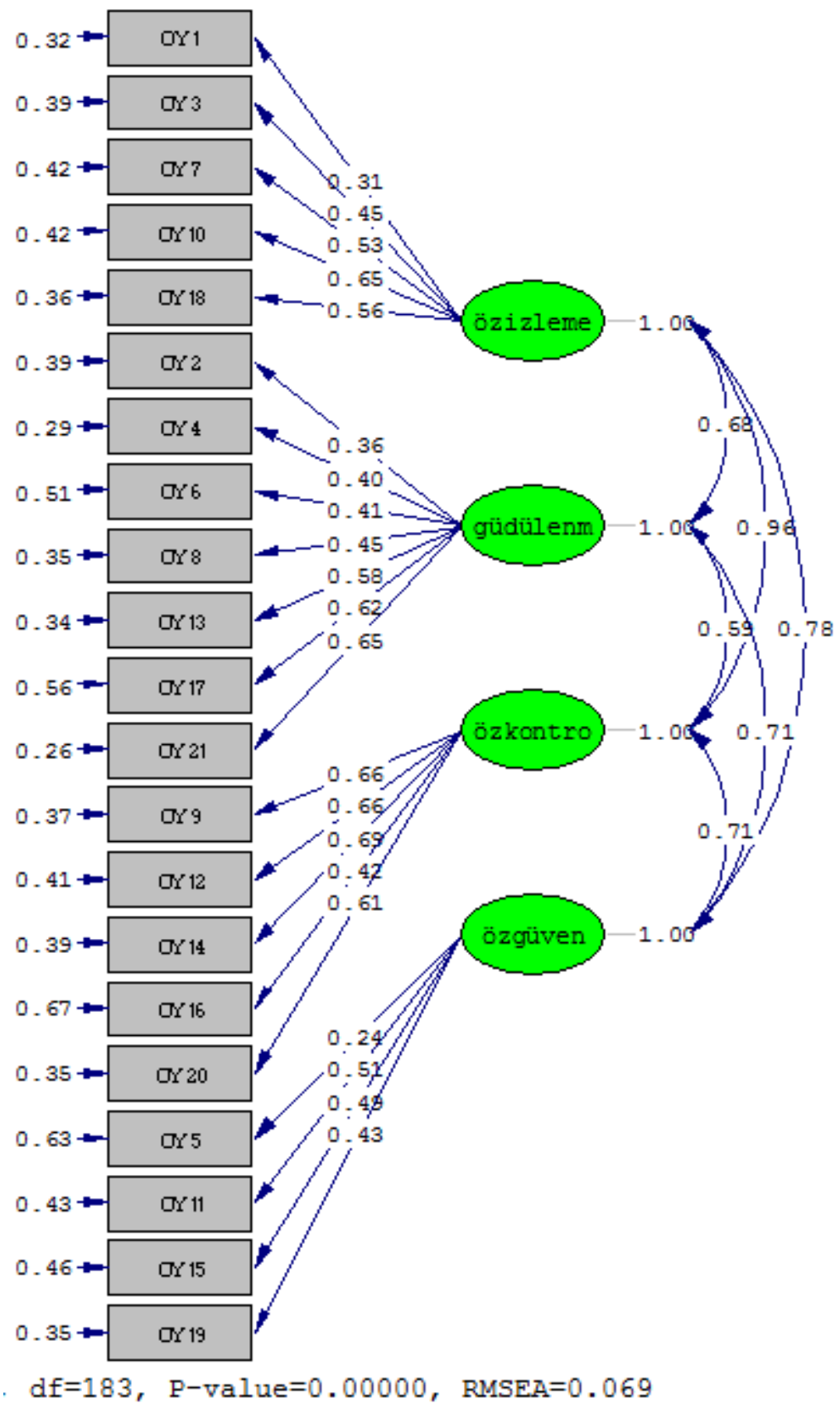

Şekil 2. “Öz Yönetimli Öğrenme Becerileri” Ölçeğine İlişkin Doğrulayıcı Faktör Analizi Sonuçları

Şekil 2 incelendiğinde, RMSEA değerinin 0,069 olduğu görülmektedir. RMSEA değerinin 0,08'den küçük olması, "kabul edilebilir bir uyum"a işaret etmektedir (Browne ve Cudeck, 1992). Bunun dışında, diğer uyum indekslerine ilişkin bilgiler Tablo 6'da verilmiştir. 
Tablo 6. Ölçeğe İlișkin Uyum İndeksleri

\begin{tabular}{ll}
\hline Uyum Ölçüleri & Ölçeğe İlişkin Uyum Değerleri \\
\hline Kikare & 2426,14 \\
sd & 183 \\
Kikare/sd & 13,26 \\
GFI & 0,92 \\
AGFI & 0,89 \\
CFI & 0,96 \\
NFI & 0,96 \\
NNFI & 0,96 \\
SRMR & 0,05 \\
RMSEA & 0,069 \\
\hline
\end{tabular}

Tablo 6 incelendiğinde, kikare değerinin 2424,14 olduğu görülmektedir. Kikare değerinin serbestlik derecesine bölünmesi sonucunda elde edilen değer 13,26'dır. Bu değerin 5 ve altında çıkması iyi bir uyum olduğunun göstergesidir (Çokluk, Şekercioğlu ve Büyüköztürk, 2012). Değerin 5'ten yüksek çıkması istenen bir sonuç değildir. Ancak, kikare değeri örneklem büyüklüğüne çok duyarlı bir değerdir (Stapleton, 1997; Marsh, Herbert ve Balla, 1986). Bunu doğrulamak amacıyla, çalışma grubunun içerisinden random olarak seçilen 1000'er kişilik verilerle de doğrulayıcı faktör analizi yapıldığında, kikare değerinin düştüğü ve serbestlik derecesine bölündüğünde değerin 5 'in altına düştüğü görülmektedir. Bu nedenle kikare değerinin serbestlik derecesine bölünmesi ile elde edilen değerin, beklenen değerlerden yüksek çıkmasının gerekçesi, çalışma grubunun büyüklüğü ile açıklanabilir. Bunun yanı sıra, doğrulayıcı faktör analizinde modele ilişkin değerlendirmenin tek bir değer üzerinden değil (özellikle kikare); birden çok uyum indeksi üzerinden yapılması gerektiği araştırmacılar tarafından da (Bentler ve Bonett, 1980; Jöreskog ve Sörbom, 1982; Stevens, 2002) önerilmektedir. $\mathrm{Bu}$ doğrultuda, ölçeğe ilişkin uyum indeksleri incelendiğinde; GFI değerinin 0,92 olduğu görülmektedir. Bu değerin 0,90-0,95 aralığında yer alması, kabul edilebilir bir uyum olduğu anlamına gelmektedir. AGFI değeri, 0,89 olarak hesaplanmıştır. Bu değerin 0,85 ile 0,90 arasında yer alması kabul edilebilir bir uyumunun olduğunun göstergesidir. Tabloda yer alan CFI değeri 0,96 bulunmuştur. CFI değerinin 0,95-0.97 aralığında olması kabul edilebilir uyum anlamına gelmektedir. NFI değeri 0,96'dır. Bu değerin 0,95 üzerinde olması iyi bir uyumun göstergesidir. NNFI değeri ise 0,96 olarak hesaplanmıştır. NNFI değerinin 0,95-0,97 arasında olması kabul edilebilir uyum olduğunu ifade etmektedir. Son olarak, SRMR değerinin 0,05 ve altında olmas1 iyi bir uyumun göstergesi sayılmaktadır. Bu değerin 0,05 bulunması, ölçeğin iyi bir uyum gösterdiği anlamına gelmektedir (Schermelleh-Engel ve Moosbrugger, 2003). Sonuç olarak, ölçeğe ilişkin uyum indekslerinin iyi uyum gösteren ve kabul edilebilir değerler arasında bulunduğu ortaya konulmuştur. Buna göre, "Öz-Yönetimli Öğrenme Becerileri”" ölçeğinin 21 maddeden oluşan 4 faktörlü yapısı, bir model olarak doğrulanmıştır.

\section{Öz-Yönetimli Öğrenme Becerileri Ölçeğinin Güvenirliği}

“Öz-yönetimli Öğrenme Becerileri Ölçeğì”nin ölçeğin güvenirliğinin belirlenmesi amaciyla Cronbach Alpha iç tutarlık katsayısı kullanılmıştır. Ölçeğin madde-toplam korelasyonları Tablo 7'de verilmiştir. 
Aşkın Tekkol, İ., Demirel, M. / Öz-Yönetimli Öğrenme Becerileri Ölçeği: Geçerlik ve Güvenirlik Çalışması

Tablo 7. Madde Toplam Korelasyonları

\begin{tabular}{|c|c|c|c|c|}
\hline & Madde Çıkarıldığında & Madde Çıkarıldığında & Düzeltilmiş $\quad$ Madde- & Madde Çıkarıldığında \\
\hline & Ölçek Ortalaması & Ölçek Varyans1 & Toplam Korelasyonu & Cronbach Alpha Değeri \\
\hline $\mathrm{m} 3$ & 80,52 & 95,231 & ,476 & 891 \\
\hline $\mathrm{m} 5$ & 80,52 & 95,114 &, 527 &, 889 \\
\hline m6 & 80,46 & 94,975 &, 531 & ,889 \\
\hline $\mathrm{m} 9$ & 80,13 & 95,243 &, 542 & ,889 \\
\hline $\mathrm{m} 10$ & 80,22 & 96,018 & ,502 & 890 \\
\hline $\mathrm{m} 12$ & 80,43 & 96,312 & ,507 & 890 \\
\hline $\mathrm{m} 13$ & 80,65 & 94,500 &, 525 & ,889 \\
\hline $\mathrm{m} 15$ & 80,09 & 96,458 & ,467 & ,891 \\
\hline $\mathrm{m} 17$ & 80,36 & 94,266 & ,575 & ,888 \\
\hline $\mathrm{m} 19$ & 80,00 & 98,055 & ,360 & ,894 \\
\hline $\mathrm{m} 25$ & 80,15 & 95,875 &, 526 & 890 \\
\hline $\mathrm{m} 26$ & 80,15 & 95,694 & ,496 & 890 \\
\hline $\mathrm{m} 30$ & 80,26 & 94,938 & ,536 & ,889 \\
\hline $\mathrm{m} 31$ & 80,86 & 93,494 & ,553 & ,889 \\
\hline $\mathrm{m} 33$ & 80,79 & 92,979 & ,548 & ,889 \\
\hline $\mathrm{m} 36$ & 80,10 & 97,261 & ,461 & ,891 \\
\hline $\mathrm{m} 38$ & 80,22 & 94,554 & ,487 & 891 \\
\hline $\mathrm{m} 42$ & 80,11 & 95,981 & ,464 & ,891 \\
\hline $\mathrm{m} 45$ & 80,37 & 96,089 & ,470 & 891 \\
\hline $\mathrm{m} 46$ & 80,55 & 94,266 & ,566 & ,888 \\
\hline $\mathrm{m} 48$ & 80,79 & 93,771 & ,531 & ,889 \\
\hline
\end{tabular}

Tablo 7 incelendiğinde, madde toplam korelasyonlarının ,360 ile ,566 arasında değiştiği görülmektedir. Her bir boyuta ilişkin güvenirlik katsayılarına ilişkin tablo ise aşağıda yer almaktadır. 
Tablo 8. Maddelerin Güvenirliklerinin Boyutlara Göre Dağılımı

\begin{tabular}{|c|c|c|c|c|c|}
\hline Maddeler & $\begin{array}{l}\text { Faktör } 1 \\
\text { Güdülenme }\end{array}$ & $\begin{array}{l}\text { Faktör } 2 \\
\text { Öz-Kontrol }\end{array}$ & $\begin{array}{l}\text { Faktör } 3 \\
\text { Öz-İzleme }\end{array}$ & $\begin{array}{l}\text { Faktör } 4 \\
\text { Özgüven }\end{array}$ & Toplam \\
\hline m17 & ,487 & & & & \\
\hline m30 &, 536 & & & & \\
\hline m38 & ,575 & & & & \\
\hline $\mathrm{m} 15$ & ,467 & & & & \\
\hline m9 &, 542 & & & & \\
\hline $\mathrm{m} 10$ & ,502 & & & & \\
\hline $\mathrm{m} 42$ & ,464 & & & & \\
\hline $\mathrm{m} 46$ & & ,548 & & & \\
\hline m33 & &, 531 & & & \\
\hline $\mathrm{m} 48$ & &, 553 & & & \\
\hline $\mathrm{m} 31$ & & , 470 & & & \\
\hline $\mathrm{m} 45$ & & ,476 & & & \\
\hline m3 & & &, 527 & & \\
\hline $\mathrm{m} 5$ & & &, 531 & & \\
\hline m6 & & &, 525 & & \\
\hline $\mathrm{m} 13$ & & & ,507 & & \\
\hline $\mathrm{m} 12$ & & & ,496 & & \\
\hline $\mathrm{m} 26$ & & & & ,496 & \\
\hline m36 & & & & ,461 & \\
\hline m19 & & & & ,360 & \\
\hline $\mathrm{m} 25$ & & & & ,526 & \\
\hline Cronbach Alpha & ,826 & ,799 & ,768 & ,690 & ,895 \\
\hline
\end{tabular}

Tablo 8 incelendiğinde, güdülenme boyutunun ,826; öz-kontrol boyutunun ,799; öz-izleme boyutunun ,768 ve özgüven boyutunun ,690 değerine sahip olduğu görülmektedir. Ölçeğin tamamına göre (21 madde) hesaplanan Cronbach Alpha iç tutarlık katsayısı ise ,895 olarak hesaplanmıştır. Bu sonuç, ölçeğin nihai formunun yüksek bir güvenirliğe sahip olduğu anlamına gelmektedir.

\section{SONUÇLAR ve TARTIŞMA}

$\mathrm{Bu}$ araştırmada, üniversite öğrencilerinin öz-yönetimli öğrenme becerilerinin belirlenmesine yönelik bir ölçek geliştirilmiştir. Ölçek geliştirilirken, geçerliğinin belirlenebilmesi amacıyla açımlayıcı faktör analizi yapılmıştır. Öncelikli olarak verilerin faktör analizi için uygun olup olmadığı KaiserMeyer-Olkin (KMO) katsayısı ve Barlett Sphericity testi ile belirlenmiştir. Verilerin faktör analizi için uygun olmasının ortaya konması üzerine, Varimaks rotasyonu ile Temel Bileşenler Analizi kullanılarak açımlayıcı faktör analizi yapılmıştır. Faktör analizi sonucunda, ölçeğin öz değeri 1'den büyük 10 faktörü olduğu belirlenmiştir.

Birden fazla boyutta yük veren maddeler toplam test korelasyonları, ortak varyansları, ölçek için kritik olmaları ve faktör yükü değeri ,32'nin altında olmalarına göre ölçekten çıkarılmışlardır. Bunun sonucunda, "Öz-Yönetimli Öğrenme Becerileri Ölçeği” 21 madde ve dört boyuttan oluşan son halini almıştır. Ölçeğin boyutları alanyazınla tutarlı olacak şekilde, güdülenme (Abd-El-Fattah, 2010; Alkan ve Erdem, 2013; Fisher, King ve Tague, 2001; Guglielmino, 1977; Stockdale ve Brockett, 2010; Teng, 2005), öz-izleme (Abd-El-Fattah, 2010; Alkan ve Erdem, 2013), öz-kontrol (Abd-ElFattah, 2010; Alkan ve Erdem, 2013; Aydede ve Kesercioğlu, 2009; Fisher ve diğerleri, 2001; Guglielmino, 1977; Lee ve Kim, 2005; Lounsbury, Levy, Park, Gibson ve Smith, 2009; McCurdy, 1973; Teng, 2005; Williamson, 2007) ve özgüven (Alkan ve Erdem, 2013; Aydede ve Kesercioğlu, 2009; Oddi, 1984; Stockdale ve Brockett, 2010) olarak isimlendirilmiştir. Maddelerin boyutlara ilişkin dağılımları incelendiğinde güdülenme boyutunda yedi madde; öz-izleme boyutunda beş 
madde; öz-kontrol boyutunda beş madde ve özgüven boyutunda ise dört maddenin yer aldığ görülmektedir. Bu faktörler ölçeğe ilişkin toplam varyans \%52,906'sını açıklamaktadırlar. Ölçek beşli likert tipinde geliştirilmiştir ve ölçekten alınabilecek en düşük puan 21, en yüksek puan ise 105 olarak hesaplanmıştır.

Açımlayıcı faktör analizinin ardından ölçeğin yapısının doğrulanması amacıyla, 2600 üniversite öğrencisinden elde edilen veriler doğrulayıc faktör analizi ile analiz edilmiş ve RMSEA değeri 0,069 bulunmuştur. Bu değer "kabul edilebilir bir uyum" olduğunun göstergesidir. Analiz sonucunda kikare değeri yüksek bulunmuştur. Bu durum çalışma grubunun büyüklüğü ile açıklanabilmektedir. Bunun doğrulanması amacıyla, çalışma grubunun içerisinden tesadüfi seçilen 1000'er kişinin verilerine de doğrulayıcı faktör analizi yapıldığında, kikare değerinin serbestlik derecesine bölündüğünde değerin 5'in altına düştüğü belirlenmiştir. Ölçeğin yapısının doğrulanması konusunda, diğer uyum indekslerinin de göz önünde bulundurulmasının önemli görülmesi nedeni ile birden çok uyum indeksi incelenmiştir. Uyum indekslerinin iyi uyum gösteren ve kabul edilebilir değerler arasında olması sebebiyle (GFI: ,92; AGFI: ,89; CFI: ,96; NFI: ,96; NNFI: ,96; SRMR: ,05) “ÖzYönetimli Öğrenme Becerileri Ölçeği”nin 21 maddeden oluşan dört faktörlü yapısı, bir model olarak doğrulanmıştır. Ölçeğe ilişkin güvenirlik katsayısı ise ,895 olarak hesaplanmıştır. Bu değer, ölçeğin güvenirliğinin yüksek olduğunu göstermektedir.

Elde edilen bulgular 1şığında, bu araştırmada geliştirilen "Öz-Yönetimli Öğrenme Becerileri Ölçeği"nin geçerli ve güvenilir bir ölçme arac1 olduğu ve üniversite öğrencilerinin öz-yönetimli ögrenme becerilerinin belirlenmesinde kullanılabileceği düşünülmektedir. Ölçekten alınan yüksek puan öz-yönetimli öğrenme becerilerinin yüksek olduğuna, alınan düşük puan ise öz-yönetimli ögrenme becerilerinin düşük olduğuna işaret etmektedir. Bu ölçek aracılığıyla öz-yönetim becerisi düşük olan öğrenciler belirlenerek onların kendi kendilerine öğrenme becerilerini geliştirmeye yönelik uygulamalar yapılabilir.

\section{KAYNAKÇA}

Abd-El-Fattah, S. M. (2010). Garrison's model of self-directed learning: preliminary validation and relationship to academic achievement. The Spanish Journal of Psychology, 13(2), 586-596.

Acar, C. (2014). Fen bilgisi öğretmen adaylarının kendi kendine ögrenme becerilerinin çeşitli değişkenler açısından incelenmesi (Yüksek lisans tezi, Pamukkale Üniversitesi, Eğitim Bilimleri Enstitüsü, Denizli). Erişim adresi: http://tez2.yok.gov.tr

Alkan, F. ve Erden, E. (2013). Kendi kendine öğrenmenin laboratuvarda başarı, hazırbulunuşluk, laboratuvar becerileri tutumu ve endişeye etkisi. Hacettepe Üniversitesi Eğitim Fakültesi Dergisi, 44, 15-26.

Aydede, M. N. ve Kesercioğlu, T. (2009). Fen ve teknoloji dersine yönelik kendi kendine öğrenme becerileri ölçeğinin geliştirilmesi. Çukurova Üniversitesi Eğitim Fakültesi Dergisi, 3(36), 53-61.

Bentler, P. M., \& Bonett, D. G. (1980). Significance tests and goodness of fit in the analysis of covariance structures. Psychological Bulletin, 88(3), 588-606.

Boyer, N. R., \& Usinger, P. (2015). Tracking pathways to success: triangulating learning success factors. International Journal of Self-Directed Learning, 12(2), 22-48.

Browne, M.W., \& Cudeck, R. (1992). Alternative ways of assessing model fit. Sociological Methods Research. 21(2), 230-258. doi:10.1177/0049124192021002005

Csapo, B. (2007). Research into learning to learn through the assessment of quality and organization of learning outcomes. The Curriculum Journal, 18(2), 195-210. doi:10.1080/09585170701446044

Çokluk, Ö., Şekercioğlu, G. ve Büyüköztürk, Ş. (2012). Sosyal bilimler için çok değişkenli istatistik SPSS ve Lisrel uygulamaları (3. bs). Ankara: Pegem Akademi.

Demir, Ö. ve Yurdagül, H. (2013). Self-directed learning with technology scale for young students: a validation study. E-International Journal of Educational Research, 4(3), 58-73.

Field, L. (1989). An investigation into the structure, validity, and reliability of Guglielmino's self-directed learning readiness scale. Adult Education Querterly, 39(3), 125-139. doi: $10.1177 / 0001848191041002004$

Fisher, M., King, J., \& Tague, G. (2001). Development of self-directed learning readiness scale for nursing education. Nurse Education Today, 21, 516-525. doi:10.1054/nedt.2001.0589

Grover, K. (2015). Online social networks and the self-directed learning experience during a health crisis. International Journal of Self-Directed Learning, 12(1), 1-15. 
Guglielmino, L. M. (1977). Development of the self-directed learning readiness scale (Unpublished Doctoral dissertation). University of Georgia, Athens.

Jennett, P. A. (1992). Self-directed learning: a pragmative view. The Journal of Contuinuing Education in the Health Professions, 12, 99-104. doi:10.1002/chp.4750120208

Jöreskog, K. G. \& Sörbom, D. (1982). Recent developments in structural equation modeling. Journal of Marketing Research, 19(4), 404-416. doi: 10.2307/3151714

Kasworm, C. E. (1983). An examination of self-directed contract learning as an instructional strategy. Innovative Higher Education, 8(1), 45-54. doi:10.1007/BF00889559

Kaufman, D. M (2003). Applying educational theory in practice. British Medical Journal, 326, 213-216.

Knowles, M. S. (1975). Self-directed learning: A guide for learners and teachers. Cambridge: Englewood Cliffs.

Kocaman, G. Dicle, A. Üstün, B. ve Çimen, S. (2004). Kendi kendine öğrenmeye hazıroluş ölçeği. I. Aktif Eğitim Kurultayı, Dokuz Eylül Üniversitesi, İzmir.

Lee, C. H., \& Kim, S. H. (2005). Development of the self-directed mathematics learning test based on Vygotsky. Journal of Korea Society of Educational Studies in Mathematics: School Mathematics, 7(3), $253-268$

Lounsbury, J. W., Levy, J. J., Park, S.H., Gibson, L., W. \& Smith, R. (2009). An investigation of the construct validity of the personality trait of self-directed learning. Learning and Individual Differences, 19(4), 411-418. doi:10.1016/j.lindif.2009.03.001

Marsh, H. W., Balla, J. R., \& McDonald, R. P. (1986). Goodness-of-fit indexes in confirmatory factor analysis: The effect of sample size. Psychological Bulletin, 103(3), 391-410.

McCurdy, D. W. (1973). An analysis of qualities of self-directedness as related to selected characteristics of I.S.C.S. students. ERIC. Erişim adresi: https://eric.ed.gov/

Merriam, S. B., Caffarella, R. S., \& Baumgartner, L. M. (2007). Learning in adulthood. San Francisco: JosseyBass.

O'Shea, E. A. (2003). Self-directed learning in nurse education: a review of the literature. Journal of Advanced Nursing, 43(1), 42-70. doi:10.1046/j.1365-2648.2003.02673.x

Oddi, L. F. (1984). Department of an instrument to measure self-directed continuing learning. (Unpublished Doctoral dissertation). Northern Illinois University, Illinois.

Salas, G. (2010). Öğretmen adaylarının kendi kendine öğrenmeye hazırbulunuşlukları (Anadolu Üniversitesi örneği). (Yüksek lisans tezi, Anadolu Üniversitesi, Eğitim Bilimleri Enstitüsü, Eskişehir). Erişim adresi: http://tez2.yok.gov.tr

Sasa, A. F. (2011). Karma ögrenme temelli özel ögretim yöntemleri dersinin fen ve teknoloji ögretmen adaylarının öz yönetimli öğrenmelerine etkisi ve çevrimiçi tartışmaların içerik analizi. (Yüksek lisans tezi, Fırat Üniversitesi, Eğitim Bilimleri Enstitüsü, Elazığ). Erişim adresi: http://tez2.yok.gov.tr

Savin-Baden, M., \& Major, C. H. (2004). Foundations of problem based learning. Cornwall: MPG Books Ltd.

Schermelleh-Engel, K., \& Moosbrugger, H. (2003). Structural equation models: Tests of significance and descriptive goodness-of-fit measures. Methods of Psychological Research Online, 8(2), 23-74.

Song, L., \& Hill, J. R. (2007). A conceptual model for understanding self-directed learning in online environments. Journal of Interactive Online Learning, 6(1), 27-42.

Spencer, J. A., \& Jordan, R. K. (1999). Learner centered approaches in medical education. British Medical Journal, 318(7193), 1280-1283.

Stapleton, C. D. (1997). Basic concepts and procedures of confirmatory factor analysis. [Çevrimiçi: http://files.eric.ed.gov/fulltext/ED407416.pdf], Erişim tarihi: 23.06.2015.

Stevens, J. P. (2002). Applied multivariate statistics for the social sciences. New Jersey: Lawrance Erlbaum Associates, Inc.

Stockdale, S. L., \& Brockett, R. G. (2004). Development of the PROSDLS: A measure of self- direction in learning based on the personal responsibility orientation model. Adult Education Quarterly. 20(10), 120

Şahin, M. S. (2013). The adaptation of self-directed mathematics learning attitude scale into Turkish. Eğitim ve Bilim, 38(169), 209-223.

Şahin, E. ve Erden, M. (2008). Özyönetimli öğrenmeye hazırbulunuşluk ölçeği’nin (ÖYÖHÖ) geçerlik ve güvenirlik çalışması. E-journal of New World Sciences Academy, 4(3), 695-706.

Şimşek, Ö. F. (2007). Yapısal eşitlik modellemesine giriş. Ankara: Ekinoks.

Tabachnick, B. G., \& Fidell, L. S. (2012). Using multivariate statistics. Boston, MA: Allyn \& Bacon/Pearson Education.

ISSN: 1309 - 6575 Eğitimde ve Psikolojide Ölçme ve Değerlendirme Dergisi 
Teng, K. H. (2005). Perceptions of Taiwanese students to english learning as functions of self-efficacy, motivation, learning activities and self-directed learning (Unpublished Doctoral dissertation). University of Idaho, Idaho.

Wingate, U. (2007). A framework for transition: supporting 'learning to learn' in higher education. Higher Education Quarterly, 61(3), 391-405.

Williamson, S. N. (2007). Development of a self-rating scale of self-directed learning. Nurse Researcher, 14(2), 66-83.

\section{EXTENDED ABSTRACT}

\section{Introduction}

The ways of obtaining and using information have substantially changed as it has become accessible from the multiple sources. This, in turn, has challenged the belief that information is unchangeable, as well as the belief that authorities have access to absolute and correct information. Therefore, the importance attached to memorization faded as conceiving the nature of knowledge and learning how to reach information, in other words learning how to learn, gained ground. Learning to learn is considered basis of principles for self-directed learning.

Self-directed learning in its largest sense refers to individuals taking initiative to identify their own learning needs, determine their learning goals, define the sources they need in order to learn, choose/use appropriate learning strategies and evaluate learning outcomes with or without help from an outsider (Knowles, 1975). In self-directed learning, the responsibility to learn shifts from an external source (teacher, etc.) to the individual. The control and active involvement of the learner in the learning process is crucial in this process (Boyer and Usinger, 2015; Grover, 2015).

The aim of this study was to develop a psychometric scale that measures self-directed learning skills. In accordance with this, a validity and reliability study was conducted to develop the scale.

\section{Method}

Content and construct validity was tested to ensure the validity of the scale. For content validity, the literature was first reviewed and a conceptual framework was established to identify the basic characteristics of the scale. Besides these characteristics, similar scale development studies conducted in and outside Turkey were examined, and interviews were held with a group of university students to decide on the items of the scale. After revealing the criteria and dimensions, a 72-item pool was formed, and views were taken from 7 Curriculum and Instruction specialists, 3 Measurement and Evaluation specialists and one Turkish Language specialist. The scale was revised in line with expert views, and a 53 item version was implemented on 753 students attending Hacettepe and Başkent Universities. In order to decide whether the data were suitable for factor analysis, the data were subjected to the Kaiser-Meyer-Olkin (KMO) coefficient and Barlett's Sphericity Test.

In order to assess the construct validity of the scale, a confirmatory factor analysis was performed with the 2600 students who studied in Hacettepe and Başkent. Prior to the confirmatory factor analysis, the Mahalonobis distances were calculated to reveal the extreme values and remove them from the study group. As a result, confirmatory factor analysis was run with 2533 students.

The Cronbach Alpha internal consistency coefficient was used to explore the reliability of the 'SelfDirected Learning Skills Scale'.

\section{Results and Discussion}

After verifying fitness for factor analysis, the Varimax Rotation and Basic Components Analysis were used for the purposes of exploratory factor analysis. Following the factor analysis, the scale 
was decided to have 10 factors with an eigenvalue over 1 . As items that had a load in more than one dimension were critical to total test correlation and common variance, these were removed from the scale one by one until a meaningful structure was achieved. In addition, items with a factor loading value below .32 were also removed from the scale. The analyses resulted in four factors with an eigenvalue above 1 . This means that the scale may have a general factor. The factors following the next three factors all have an eigenvalue below 1. These factors were ignored and the scale was accepted to have 4 dimensions. The total scale variance explained by these factors was $52,906 \%$. Factors were named according to the literaure; motivation, self-control, self-monitoring and selfconfidence.

Confirmatory factor analysis was run on data from 2533 students and RMSEA value was calculated of 0,069. An RMSEA value below 0,08 showed 'acceptable fit'. Chi square value was found 2424,14 . The value obtained by dividing the chi square value by the degree of freedom was 13,26. This value being five or below shows good fit (Çokluk, Şekercioğlu and Büyüköztürk, 2012). A value over five is not desired. However, chi square value is highly sensitive to sample size (Stapleton, 1997; Marsh, Balla and McDonald, 1986). In order to confirm this, a confirmatory factor analysis was also run on data from 1,000-individual groups selected randomly from among the study sample, as a result of which the chi square value dropped and its division into the degree of freedom yielded in a value below five. Therefore, the high sum resulting from the division of the chi square value into the degree of freedom may be explained with the size of the study group. In addition, researchers also recommend that model evaluation in confirmatory factor analysis should be done not over a single value (particularly chi square), but over multiple fit indices (Bentler and Bonett, 1980; Jöreskog and Sörbom, 1982; Stevens, 2002). The fit indices of the scale were shown to range between good and acceptable values (Schermelleh-Engel and Moosbrugger, 2003). According to this, the 21-item and four-factor structure of the 'Self-Directed Learning Skills Scale' was confirmed as a model.

The internal consistency of the items for the different sub-dimensions of the scale were calculated: The motivation subdimension was .826, in self-control .799, in self-monitoring .768, and in selfconfidence .690. The Cronbach Alpha internal consistency coefficient for the entire scale (21 items) was .895 , suggesting that the items in the final version of the scale had high internal consistency. Exploratory factor analysis was implemented and it was found the scale consisted 21 item and 4 factors (motivation, self-control, self-monitoring and self-confidence). 